\title{
白鹤迁徙动态及其停歇地环境条件研究
}

\author{
何春光 ${ }^{1}$ 宋榆钧 ${ }^{2}$ 郎惠卿 ${ }^{1}$ 李鸿凯 ${ }^{1}$ 孙孝维 ${ }^{3}$ \\ 1 (东北师范大学城市与环境科学学院, 长春 130024) \\ 2 (东北师范大学生命科学学院, 长春 130024) \\ 3 (莫莫格国家级自然保护区管理局，吉林白城 137000)
}

摘要 : 在吉林省莫莫格保护区于 2000 年 $4 \sim 5$ 月对途经此地的白鹤 (Grus leucogeranus) 种群数量和停歇地环境条件 进行研究的结果表明: 白鹤于 4 月 3 日左右迁来, 高峰期在 4 月下旬, 最多数量达到 577 只 (4 月 27 日), 5 月 8 日 离开莫莫格, 停歇期 36 天。白鹤迁徙活动受风速、气温、降雨等天气条件影响。喜栖湿草甸、浅水湖泡及湖泡中间 的旱堑”。取食鱼类及植物，以植物性食物为主。本文提出了进一步研究和保护白鹤迁徙停歇地的措施。 关键词: 白鹤, 迁徙动态, 停歇地环境条件

中图分类号:Q16,Q958.13文献标识码:A 文章编号 : 1005-0094(2002)03-0286-05

\section{Migratory dynamics of Siberian crane and environmental conditions at its stop-over site}

HE Chun-Guang ${ }^{1}$, SONG Yu-Jun ${ }^{2}$, LANG Hui-Qing ${ }^{1}$, LI Hong-Kai ${ }^{1}$, SUN Xiao-Wei ${ }^{3}$

1 Urban and Environment Science College , Northeast Normal University, Changchun 130024

2 Life Science College, Northeast Normal University, Changchun 130024

3 Momoge Nature Reserve, Baicheng 137000

\begin{abstract}
From April to May 2000 , we investigated the number of Siberian crane and environment condition at their stop-over site in Momoge Nature Reserve. The Siberian cranes arrive at Momoge Nature Reserve on about April 3 and leave on May 8. The period of stop-over is 36 days. Most of the cranes arrive here during the end of April, and the largest number reaches 577 individuals on April 27. The activity of cranes is affected by weather condition, such as wind velocity, temperature, and rainfall. Most cranes are distributed in wet meadow, shallow water and at Hanqian in the middle of ponds. They mainly feed on plants, and also on fish in this area. We offer some recommendations for measures for research and conservation of Siberian crane.
\end{abstract}

Key words : Siberian Crane, migratory dynamic, environment condition of stopover

白鹤又名西伯利亚鹤 (Grus leucogeranus) ,是世 界上仅次于美洲鹤和丹顶鹤的珍稀濒危鹤类之一， 也是我国的 I 级保护动物。白鹤是一种迁徙性鸟 类, 主要分布在亚洲大陆, 目前全世界仅有 3000 余 只, 以中国数量最多,近年来, 中国越冬白鹤种群数 量占世界种群数量的近 99\% (Meine \& Archibald， 1996 ;苏化龙等 2000)。共分为西部种群、中部种群 和东部种群。其中西部种群在伊朗越冬,数量较少， 1996 年仅观察到 4 只; 中部种群在印度越冬,数量
也不多 20 世纪 80 年代中后期也仅有 9 11 只, 目 前这 2 个种群数量都有所减少; 东部种群主要在我 国江西省的鄱阳湖等地越冬 (Meine \& Archibald, 1996 ）近年来已发现来这里的白鹤有 2896 只之多， 占全球白鹤总数的 $98 \%$ 以上 (苏化龙等, 2000)。每 年春季,东部种群由鄱阳湖起飞, 经松嫩平原的向 海、莫莫格、扎龙等地(见图 1) 约 6 月份到达西伯 利亚东北部繁殖, 10 月份携幼鸟返回鄱阳湖越冬 ( 杨兆芬，1986)。 


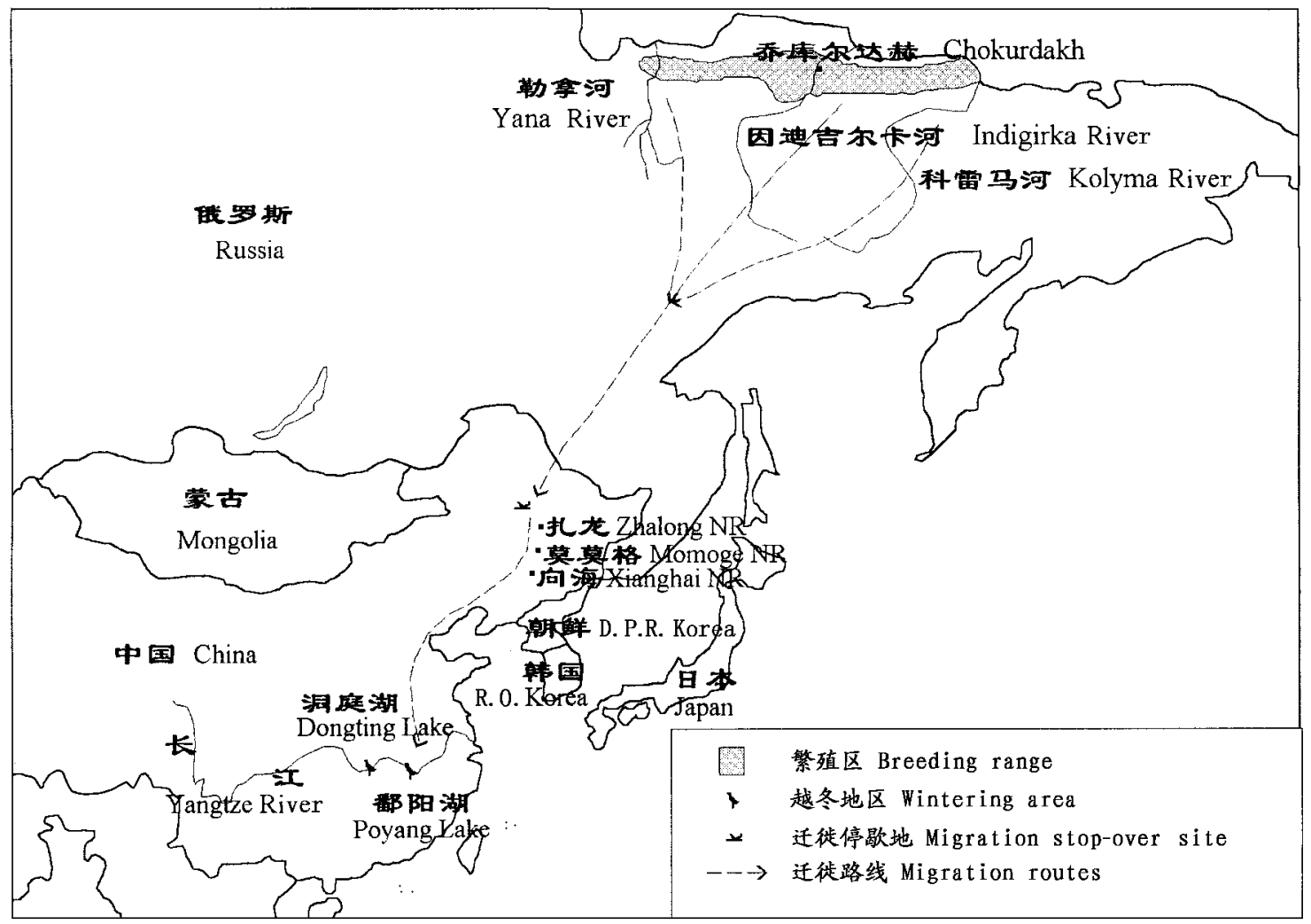

图 1 白鹤东部种群迁徙路线示意图 (仿 Meine \& Archibald ,1996)

Fig. 1 The migration routes of Siberian crane (Eastern population)

白鹤是一种完全依赖湿地而生存的鸟类,近年 来，由于人类对湿地资源的过度开发，如围唇、放牧、 采油等,使白鹤赖以生存的生境日益减少和遭到破 坏，白鹤的数量也在下降。为了解白鹤在迁徙期种 群数量的变化及其与环境条件的关系,我们在莫莫 格自然保护区 (图 1 ) ,对白鹤的迁徙动态及其停歇 地的环境条件进行了详细的观察、观测。

\section{1 研究区域自然概况}

莫莫格自然保护区的地理座标为 $45^{\circ} 45^{\prime} \sim 46^{\circ} 10^{\prime}$ $\mathrm{N}, 122^{\circ} 27^{\prime} \sim 124^{\circ} 4^{\prime} \mathrm{E}$ 。该区总面积为 14.4 万 $\mathrm{hm}^{2}$, 发源于大兴安岭依勒乎里山的嫩江, 在本区的流域面 积为 3 万余公顷 发源于大兴安岭索尔乔山的南部界 河洮儿河，在本区的流域面积为 7 万余公顷。尚有季 节性河 2 条，即二龙涛河、呼尔达河，分别汇入洮儿河 与嫩江, 因此湿地面积广阔, 达 11 万多公顷, 几乎占 保护区面积的 90\%以上(王里, 吴志刚,1989)，为鹤 类等珍稀水禽的栖息繁殖提供了良好的生存环境。 该区平均海拔 $142 \mathrm{~m}$ 左右, 属大陆性季风气候, 年均 温 $4.2{ }^{\circ} \mathrm{C}$, 年均降雨量为 $377.1 \mathrm{~mm}$ 。

\section{2 研究方法}

自 2000 年 3 月 15 日起, 我们对莫莫格自然保 护区所辖的五棵树、东屏、沿江、大屯、莫莫格、岔台、 古鲁台、隋家围子、后各力吐、棉西屯、他四海、胡家 窝棚、杨沙泡、哈尔挠、二龙梭口小东屯、三门王家、 元宝吐等 6 个乡镇的十几个村屯进行了全方位的实 地调查和现场访问，根据白鹤的分布情况，确定三门 王家 (天鹅湖)、后各力吐为观测样点, 从 4 月 16 日 开始至 5 月 10 日止, 采取定点观测的方法(张金屯， 1999 ）,对鹤类的迁徙动态及其停歇地环境条件进 行逐日观察,对其种群数量的统计采用直接计数法。

\section{3 研究结果}

\section{1 白鹤迁徙动态}

最早观测到白鹤的时间为 4 月 9 日, 位置在三 门王家小桥西南方向约 $400 \mathrm{~m}$ 处的一个小泡中, 只 发现 1 对。4 月 11 日, 在东屏镇后各力吐村西河桥 南的水泡中, 发现一个 107 只的白鹤群。据当地居 民讲，该群白鹤约 1 周前来到此地，因此估计白鹤是 
在 4 月 3 日左右到达莫莫格自然保护区。

从 4 月 16 日 $~ 5$ 月 10 日, 对后各力吐村和三 门王家的白鹤进行定点观测，结果见表 1 。由表 1 可以看出, 此期白鹤的数量变动较大, 16 19 日, 白 鹤数量在 $100 \sim 200$ 只之间; $20 \sim 22$ 日数量骤减至 十几只 23 日数量为 0 ,仅在空中发现 2 只白鹤向西 南方向飞去。白鹤可能因这几天降雨而转移他地 或已向北迁走。24 26日，在西河西岸 $3 \sim 4$ 里远 的草甸上,发现有分散活动的几个家族群。24日数 量最多，一共 9 个家族群 35 只。4 月 27 日早 6: 17 于西河桥头发现 2 群共 38 只白鹤由西南向东北飞 去,估计是迁往北方。下午 3:00 顺着后各力吐村 的西南方向，在大草甸上行走约 $3 \sim 4 \mathrm{~km}$, 在一个被 当地人称作西南泡的泡中及其南岸的盐碱草甸上 发现了 1 个大的白鹤群，共 528 只,加上早晨和上午 观测到的,4月27日共见白鹤577只,为以往所

表 12000 年春季莫莫格自然保护区迁徙白鹤的数量日变 化(只/日)

Table 1 Changes in number of migratory Siberian crane (ind./ day )

\begin{tabular}{|c|c|c|c|}
\hline \multirow{2}{*}{$\begin{array}{c}\text { 日期 } \\
\text { Month/date }\end{array}$} & \multicolumn{3}{|c|}{ 位置 Location } \\
\hline & $\begin{array}{c}\text { 三门王家 } \\
\text { Sanmenwangjia }\end{array}$ & $\begin{array}{l}\text { 后各力吐 } \\
\text { Hougelitu }\end{array}$ & $\begin{array}{l}\text { 总数 } \\
\text { Total }\end{array}$ \\
\hline $4 / 16$ & 6 & 147 & 153 \\
\hline $4 / 17$ & 6 & 132 & 138 \\
\hline $4 / 18$ & 3 & 192 & 195 \\
\hline $4 / 19$ & 0 & 98 & 98 \\
\hline $4 / 20$ & 3 & 18 & 21 \\
\hline $4 / 21$ & 3 & 13 & 16 \\
\hline $4 / 22$ & 3 & 14 & 17 \\
\hline $4 / 23$ & 0 & 0 & 0 \\
\hline $4 / 24$ & 0 & 35 & 35 \\
\hline $4 / 25$ & 3 & 8 & 11 \\
\hline $4 / 26$ & 0 & 14 & 14 \\
\hline $4 / 27$ & 0 & 577 & 577 \\
\hline $4 / 28$ & 0 & 506 & 506 \\
\hline $4 / 29$ & 0 & 448 & 448 \\
\hline $4 / 30$ & 0 & 245 & 245 \\
\hline $5 / 1$ & 0 & 207 & 207 \\
\hline $5 / 2$ & 0 & 204 & 204 \\
\hline $5 / 3$ & 0 & 136 & 136 \\
\hline $5 / 4$ & 0 & 112 & 112 \\
\hline $5 / 5$ & 0 & 87 & 87 \\
\hline $5 / 6$ & 0 & 45 & 45 \\
\hline $5 / 7$ & 0 & 45 & 45 \\
\hline $5 / 8$ & 0 & 43 & 43 \\
\hline $5 / 9$ & 0 & 0 & 0 \\
\hline $5 / 10$ & 0 & 0 & 0 \\
\hline
\end{tabular}

罕见。4 月 27 日 5 月 8 日, 白鹤数量日渐减少, 4 月 29 日早晨飞走的最大一群约 200 只。随着 5 月 8 日最后一群 43 只白鹤飞离此地后, 再末见有白鹤。 因此, 白鹤在 2000 年春季的迁经期共历时 36 天。

三门王家的白鹤数量一直不多, 最多时为 4 月 10 日, 一共 16 只, 平时只有 $1 \sim 3$ 个家族群在此活 动, 4 月 26 日后, 再未见有白鹤活动。

\section{2 白鹤停歇地环境条件}

3.2.1 气候条件 根据镇㐘县气象台的资料, 2000 年 4 月 (即白鹤迁徙期) 的平均气温为 $7.67 \pm 3$. $20^{\circ} \mathrm{C}$, 平均湿度为 $42.03 \pm 21.55 \%$, 平均风速为 4.1 $\pm 71.77 \mathrm{~m} / \mathrm{s}$ 。整个观测期间, 只是在 4 月 $20 、 21$ 、 $22 、 23$ 这 4 天有少量降雨, 降雨量分别为 $11.6 \mathrm{~mm}$ 、 $16.2 \mathrm{~mm} 、 1.8 \mathrm{~mm}$ 和 $0.4 \mathrm{~mm}$,总量为 $30.0 \mathrm{~mm}$ 。白 鹤迁来时 (4 月 3 日) 的日平均气温为 $10.3^{\circ} \mathrm{C}$, 迁走 时 (5 月 8 日) 日平均气温为 $15.0^{\circ} \mathrm{C}$ 。在观测中还发 现, 在气温较低, 凤速较大的天气, 白鹤会出现集大 群现象, 很少有分散家族独自活动, 而且取食时间缩 短, 休息停留时间变长。在降雨期间, 白鹤数量减 少, 大群白鹤发生转移。

3.2.2 水环境特征 白鹤的栖息离不开水。通过 实地观察发现, 小群或成家族的白鹤主要活动于一 些分散的浅水小泡中 (见表 2 ), 水深多为 $2 \sim 10 \mathrm{~cm}$ 。 大群白鹤分布的地方, 如后各力吐, 水域面积也较 大, 水相对较深, 为 $10 \sim 30 \mathrm{~cm}$ 。水的 $\mathrm{pH}$ 值在 $7.0 \sim$ 8.0 之间, $\mathrm{pH}$ 值较大的水泡很少有白鹤分布。白鹤 栖息的水泡基本为静态水,但到了雨季, 部分水泡变 为流动水, 形成漫流, 如后力吐的西河。白鹤在水中 或软泥滩中取食时,均需将豚取的植物根芽或球茎 在水中漂浣, 然后再吃。在没有水仅有软泥滩的地 方, 虽然也生长着香蒲和扁杆蔍, 白鹤却很少光顾。 可见水对白鹤栖息取食有着极为重要的作用。

在观测期间，对白鹤停歇地的水温共进行 12 天 的观测, 平均水温为 $10.34 \pm 4.77^{\circ} \mathrm{C}$ 。

3.2.3 植被特征白鹤停歇地的植被有草甸、泥滩 植物群落及浅水植物群落。各种植物群落以湖泡为 中心, 随水位变化呈环状有规律地分布。水深处为 明水面, 湖边浅水泥滩上有东方香蒲( Typha orientalis) 群落, 向外地势较高地段为草甸, 局部盐碱地 有碱蓬 (Suaeda glauca) 盐沼。

在水域面积较大的泡沼中间，分布有略高于水 面 $(5 \sim 20 \mathrm{~cm})$ 的陆地, 被当地老百姓称为 旱堑”。 
在后各力吐西河的漫流区，局部低洼地段形成的大 面积的泡沼中间，分布有面积大小不等、形状各异的 “旱堑”。有的 旱堑”为松软的泥滩地, 生长有香蒲 群落，或香蒲 - 芦苇 (Phragmites communis) 群落; 地 势较高的旱堑”上, 植物群落呈环带状分布。采用 植物群落样方法, 对呈带状分布的植物群落进行取 样, 样方为 $1 \times 1 \mathrm{~m}^{2}$, 每种植物群落取 5 个样方, 测量 植物群落的高度、密度、盖度等, 结果见表 3 。

由表 3 可以看出, 蒿草 (Thearvillea sinensis) 群 落的高度及密度均为最大, 它们生长在 旱堑” 的最 高层, 在大风天气, 白鹤可凭此躲避强劲的风力。隐 花草 (Crypsis aculeatu) 和狐尾草 (Chloris virgata) 群 落的盖度都比较大, 但高度小,由于生长太密, 未进 行密度统计, 2 种群落构成草甸景观。水中香蒲密 度最小, 为 $12.6 \pm 7.5$ 株 $/ \mathrm{m}^{2}$, 扁杆蔗草群落的密度
虽然较大, 但盖度和高度均小。香蒲、扁杆蔍草 (Scirpus planiculmis)、碱蓬等群落是白鹤经常取食 的地方。“旱堑”距最近的岸边有 $100 \mathrm{~m}$ 左右, 少有 人类干扰, 是白鹤比较理想的取食栖息地。

3.2.4 食物条件 捡拾白鹤粪便, 发现外面有薄薄 的一层灰白色、质细软的物质, 可能是已消化的动物 性食物。根据我们对后各力吐西河水泡中动物的调 查, 泡中主要生长有体长为 $5 \sim 10 \mathrm{~cm}$ 的小鲫鱼、葛 氏鲈塘鲤 (老头鱼)、泥鳅等鱼类, 它们很可能是白 鹤在此停歇所需的动物性食物来源。粪便内层绝大 部分呈灰绿色、质粗硬, 含有植物纤维, 可推测白鹤 在这里以植物性食物为主。通过进一步观察白鹤取 食过的泥滩地, 发现在香蒲和扁杆蔍草的根部有白 鹤豚食的痕迹。挖出香蒲和扁杆蔍草的根部, 发现 香蒲已长出近 $3 \mathrm{~cm}$ 的嫩芽, 扁杆蔗草的球状茎剥去

表 2 白鹤停歇地的水环境

Table 2 The water environment of Siberian crane's stop-over site

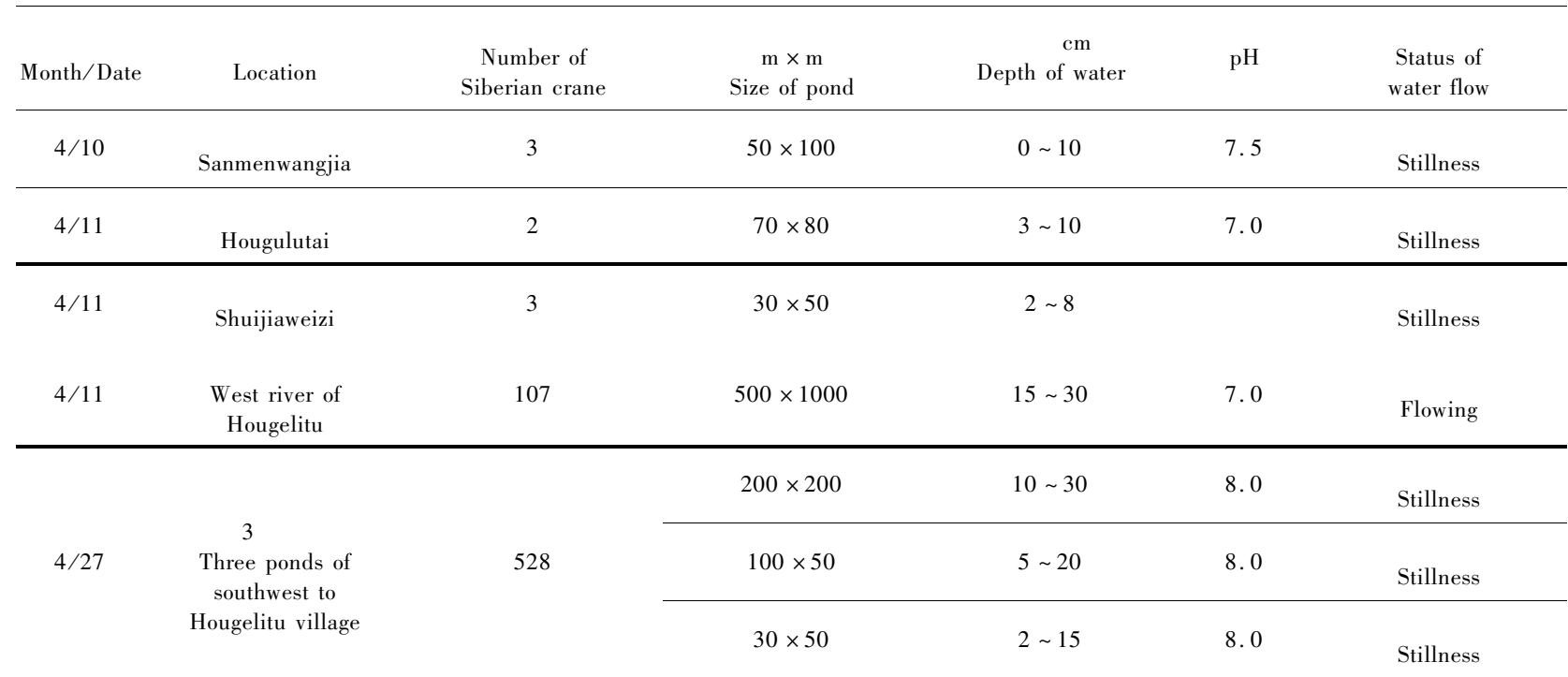

表 3 白鹤停歇地植物群落特征

Table 3 The characteristic of plant community of Siberian crane' s stop-over site

\begin{tabular}{lcrr}
\hline \multicolumn{1}{c}{$\begin{array}{c}\text { 群落类型 } \\
\text { Type of plant community }\end{array}$} & $\begin{array}{c}\text { 高度 }(\mathrm{cm}) \\
\text { Height }\end{array}$ & $\begin{array}{c}\text { 密度 }\left(\text { 株 } / \mathrm{m}^{2}\right) \\
\text { Density }\left(\text { inds. } / \mathrm{m}^{2}\right)\end{array}$ & $\begin{array}{c}\text { 盖度 }(\%) \\
\text { Coverage }\end{array}$ \\
\hline 水中香蒲群落 Community of Typha orientalis in pond & $6.2 \pm 2.1$ & $12.6 \pm 7.5$ & $26.0 \pm 11.0$ \\
泥滩香蒲群落 Community of Typha orientalis in land & $21.0 \pm 4.6$ & $33.4 \pm 9.5$ & $39.0 \pm 8.9$ \\
扁杆蔍草群落 Community of Scirpus planiculmis & $4.6 \pm 1.8$ & $77.8 \pm 13.0$ & $20.0 \pm 7.9$ \\
隐花草群落 Community of Crypsis aculeatu & $2.3 \pm 0.9$ & & $68.0 \pm 13.0$ \\
碱蓬群落 Community of Suaeda glauca & $56.7 \pm 13.9$ & & $20.0 \pm 9.4$ \\
狐尾草群落 Community of Chloris virgata & $2.3 \pm 0.6$ & & $72.0 \pm 9.1$ \\
旱堑蒿草群落 Community of Thcarvillea sinensis & $81.7 \pm 15.1$ & $82.2 \pm 6.8$ & $30.0 \pm 7.1$ \\
\hline
\end{tabular}


外皮, 内部是松脆的白色果实, 很适合白鹤取食。另 外，在 4 月 27 日发现的 528 只大群白鹤栖息的草甸 上, 主要生长的是碱蓬, 并伴生有蒲公英( Taraxacum sinicum)。碱蓬的根茎和蒲公英的嫩芽也是白鹤较 好的植物性食物来源。在观察中还发现, 白鹤足迹 的数量与香蒲和扁杆芧草的密度具有一定的正相 关。这可以作为白鹤以植物性食物为主的一个有力 证据。

\subsection{5 人为活动对白鹤的影响}

在莫莫格自然保护区内, 居民生活除种植作物 外, 主要以放牧为主。区内牛、马、羊群等随处可见。 通过跟踪观察发现, 放牧对白鹤的活动影响不大。 白鹤的栖息生境主要为湿草甸、浅水泡沼，经常可看 到白鹤与牛、马、羊群之间的活动关系较为协调, 彼 此保持一定间距, 互不干扰, 个别白鹤种群还会与牧 群混杂, 和睦共处。大群白鹤偶而受到牧群的冲击， 虽有轻微的骚乱, 但很快恢复正常。而人与白鹤相 距 $200 \mathrm{~m}$ 时, 鹤群即会发生骚乱, 并很快起飞。

\section{4 对白鹤进行研究和保护的措施和策略}

\section{1 继续做好白鹤的迁徙动态监测工作}

莫莫格自然保护区是白鹤迁徙路线上的重要停 歇地, 每年都有大群的白鹤在此停歇路过 (王里, 吴 志刚，1986），迁徙期 40 多天。2000 年春季，日最高 种群数量达到 577 只, 迁徙期 36 天。因此, 建议在 莫莫格自然保护区后各力吐至三门王家一带建立定 位观测站, 每年春秋两季观察观测白鹤的种群数量、 种群结构及变化趋势。

\section{2 加强对白鹤停歇地环境条件的进一步研究}

莫莫格自然保护区作为白鹤迁徙的一个重要停 歇地, 甚至被称为白鹤的 第三故乡”。从今年观测 的结果来看, 白鹤种群数量达到该区记录的历史高 峰, 主要分布于三门王家、后古鲁台、后各力吐等区 域的浅水泡沼和湿草甸中。据宋榆钧等对向海和李 晓民等对扎龙和哈拉海的观察 ${ }^{(1)}$, 白鹤在这 3 个地 区的数量不多(《鹤类通讯》2001 年第 1 期报道)， 尤其是扎龙, 在 1984 1996 年间, 每年有 400 多只 白鹤在扎龙停留,可是 2000 年春季却仅见到 2 次，
计 82 只。今年白鹤数量集中于莫莫格保护区, 分布 区缩小, 这说明其他地区水环境发生了很大变化, 即 由于干旱或人为活动造成大多数的浅水泡沼干涸， 环境恶化, 适合其栖息停留的地方减少, 从而使莫莫 格保护区白鹤数量比往年增加。同时也说明在莫莫 格保护区还有适合白鹤栖息的良好生境, 需要对其 栖息地的水文状况、植被条件、白鹤的食物来源等条 件进一步研究, 以评估白鹤停歇地的环境状况。白 鹤的生活离不开水, 水中的鱼类及依赖水而生存的 各种植物是白鹤迁徙所需的食物来源, 因此如何解 决栖息地水源问题, 尤其是在象莫莫格这样干旱的 地区, 如何利用洪水来解决水源问题, 是我们今后需 要进一步研究的课题。

\section{3 加强对白鹤停歇地的保护和管理}

在白鹤停歇地存在大量的人为活动, 大量牧群 践踏湿草甸和浅水泡沼, 农民在湿草甸和浅水泡沼 周围开星土地, 这样势必破坏白鹤的取食生境。另 外, 当地农民打鸭子、大雁等现象还时有发生, 白鹤 受到枪声惊扰, 不得不转移他地, 使其取食活动范围 大大减少。因此, 需要在保护区内进行保护宣传, 让 当地居民认识到保护鹤类及其停歇地的重要意义, 并引导他们走环境保护与经济发展相协调的道路， 使他们能自发的参与到保护行动中来。在鹤类迁徙 停歇地的重点区域, 设立保护站, 加强管理, 对那些 继续违法犯罪的猎捕分子要进行严厉打击, 不断提 高当地居民的法制观念。

\section{参考文献}

苏化龙, 林英华, 李迪强, 钱法文, 2000. 中国鹤类现状及其 保护对策. 生物多样性, 8(2): 180 191

王里, 吴志刚, 1989. 莫莫格自然保护区. 北京: 中国林业出 版社, $12 \sim 13$

杨兆芬, 1986. 世界的鹤类. 见: 马逸清 (主编), 中国鹤类 研究文集. 哈尔滨: 黑龙江教育出版社, $243 \sim 244$

张金屯( 译), 1999. 生态学调查方法手册. 北京: 科学技术 文献出版社, $270 \sim 272$

Meine C D and G W Archibald, 1996. The Cranes Status Sruvey and Conservation Action Plan. IUCN, $263 \sim 265$

(责任审稿人 :王岐山; 责任编辑 : 间文杰) 